\title{
FROM THE EDITOR..............
}

Dream of every Civil Engineer is to design an innovative structure, which when built would serve its purpose safely throughout its life span. This dream could easily turn into a nightmare if the structure fails in serviceability or catastrophically due to flawed design assumptions, constructional lapses or extreme natural conditions. But when a designed and built structure faces an envisaged extreme condition and passes through it as intended, the designers as well as constructors could indeed congratulate themselves.

A living example of this scenario was unveiled to us recently, when due to extremely heavy weather experienced by the country in decades, the inflow to the Victoria reservoir forced it to spill extensively, close to maximum capacity, by automatic opening of all six spill gates in the dam. The double curvature mass concrete arch dam which is both a Civil Engineering and Aesthetic masterpiece had been provided with six hydraulically controlled spill gates designed to automatically operate based on the water level and safely release the inflow. As envisaged by the design Engineers, the gates functioned as intended, safely discharging the waters, while as a bonus creating such a spectacular sight to the beholders.

The Engineers involved in the design and construction of this dam should certainly be happy people who have got their assumptions in design practically verified. All of us might not get the opportunity to verify our designs under extreme conditions, but if the chance presents itself with positive results, it in itself is rewarding.

Eng. (Prof.) T. M. Pallewatta, Int. PEng (SL), C. Eng, FIE(SL), FIAE(SL)

Editor, 'ENGINEER', Journal of The Institution of Engineers.

Editor, Technical Papers for the Transactions of The Institution of Engineers. 